\title{
PREDICTION OF CHANGES IN VEGETATION DISTRIBUTION UNDER CLIMATE CHANGE SCENARIOS USING MODIS DATASET
}

\author{
Hidetake Hirayama $^{\text {a*}}$, Mizuki Tomita ${ }^{\mathrm{b}}$, Keitarou Hara ${ }^{\mathrm{b}}$ \\ ${ }^{a}$ Graduate School of Tokyo University of Information Sciences, 4-1Onaridai, Wakaba-ku, Chiba, 265-8501 Japan - \\ g15006hh@edu.tuis.ac.jp \\ b Tokyo University of Information Sciences, 4-1Onaridai, Wakaba-ku, Chiba, 265-8501 Japan
}

Commission VIII, WG VIII/8

KEY WORDS: MODIS, Beech, Prediction modelling, Climate change

\begin{abstract}
:
The distribution of vegetation is expected to change under the influence of climate change. This study utilizes vegetation maps derived from Terra/MODIS data to generate a model of current climate conditions suitable to beech-dominated deciduous forests, which are the typical vegetation of Japan's cool temperate zone. This model will then be coordinated with future climate change scenarios to predict the future distribution of beech forests. The model was developed by using the presence or absence of beech forest as the dependent variable. Four climatic variables; mean minimum daily temperature of the coldest month (TMC), warmth index (WI), winter precipitation (PRW) and summer precipitation (PRS): and five geophysical variables; topography (TOPO), surface geology (GEOL), soil (SOIL), slope aspect (ASP), and inclination (INCL); were adopted as independent variables. Previous vegetation distribution studies used point data derived from field surveys. The remote sensing data utilized in this study, however, should permit collecting of greater amounts of data, and also frequent updating of data and distribution maps. These results will hopefully show that use of remote sensing data can provide new insights into our understanding of how vegetation distribution will be influenced by climate change.
\end{abstract}

\section{INTRODUCTION}

According to predictions by the fourth assessment report of IPCC, it is believed that the world average surface temperature will rise by about 1.8 to $4.0^{\circ} \mathrm{C}$ by the end of $21^{\text {st }}$ century (IPCC, 2007). Impacts of this climate change include not only rising temperatures, but shifts in the amount and timing of precipitation as well. Climate change can thus be expected to have a severe impact on various types of ecosystem (IPCC, 2007).

As one study on the effect of climate change on ecosystems, future changes in forest distribution areas were predicted by modelling a potential distribution area of natural forests, especially Japanese beech forests (Matsui et al., 2004, 2009). These results of these predictions can be utilized for planning countermeasures against future ecological changes and their associated impacts.

These predictive studies, however, relied on vegetation maps produced by the Ministry of Environment (MOE) National Survey on the Natural Environment. The MOE maps are based on detailed field surveys supplemented by interpretation of vegetation based on aerial and satellite photographs. This process is cumbersome and time-consuming, and difficult to implement in some areas of rough terrain or accumulated snow. As a result the MOE maps are often incomplete or out of date. Even in case of the relatively new dataset produced by the fifth National Survey on the Natural Environment, the corresponding survey period was from 1994 to 1998, a gap of about 20 years from today. In recent years, classification of remotely sensed data, which is able to cover a wide area and can be easily updated, has been identified as a means of coping with the limitations of conventional mapping processes (Hioki, 2007). At Tokyo University of Information Science (TUIS), nation-wide land cover classification maps (hereinafter referred to as "present vegetation map") have been developed using MODIS data, which is available frequently and over a wide geographic area. In the current study, the present vegetation map is employed to analyse future vegetation shifts based on forecasted climate change. The results are compared with those derived from existing vegetation maps, with the goal of demonstrating the effectiveness of MODIS data as a tool for wide scale prediction of future vegetation changes.

\section{DATA AND METHODS}

\subsection{Prediction model of beech-dominated deciduous forests}

The variables in the model of distribution of beech-dominated deciduous forests used in this study was based on the ENVI model developed by Matsui et al. (2004). The model uses the presence or absence of beech forest as the dependent variable. Four climatic variables; mean minimum daily temperature of the coldest month (TMC), warmth index (WI), winter precipitation (PRW) and summer precipitation (PRS): and five geophysical variables; topography (TOPO), surface geology (GEOL), soil (SOIL), slope aspect (ASP), and inclination (INCL); were adopted as independent variables. This model is designed to extract spatially explicit sites suitable for growth of beech-dominated deciduous forests.

This study first established the data sets for the model, then correlated the current presence/absence of beech forest data with the data on current climate and geophysical conditions. This allowed for identification of the conditions suitable for growth of these forests. The future distribution of beech forests was then predicted using the model with the data sets for future climate conditions.

\footnotetext{
* Corresponding author
} 


\subsection{Data for vegetation distribution}

The present vegetation map used in this study is a MODISbased national scale land cover classification map created by TUIS with regular updates at three to five-year intervals. The map was generated by the ISODATA method (non-hierarchical cluster analysis), using monthly composite images of vegetated areas and non-vegetated areas derived from a total of 63 bands MODIS datasets (Harada et al., 2015). The flow chart for creating the maps is shown in Figure 1.

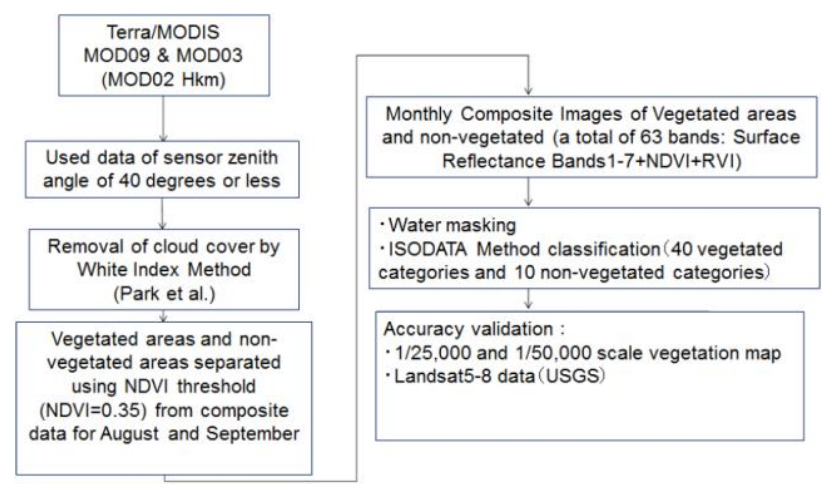

Figure 1. Flowchart for constructing vegetation maps from Terra/MODIS data. (Harada et al., 2015)

In this study, the distribution of presence/absence of beech forest was generated from the present vegetation map. In addition, the data was converted to $1 \mathrm{~km} \times 1 \mathrm{~km}$ third mesh to standardize it with the other datasets. Each mesh was evaluated as presence or absence based on whether or it contained beech forest.

The distribution map was shown in Figure 2. The original results showed the presence of beech forest in parts of Hokkaido that are beyond the known northern limit of these forests; Kuromatsunai Lowland (Yamagishi \& Kimura, 1981). These meshes were thus changed from presence to absence.
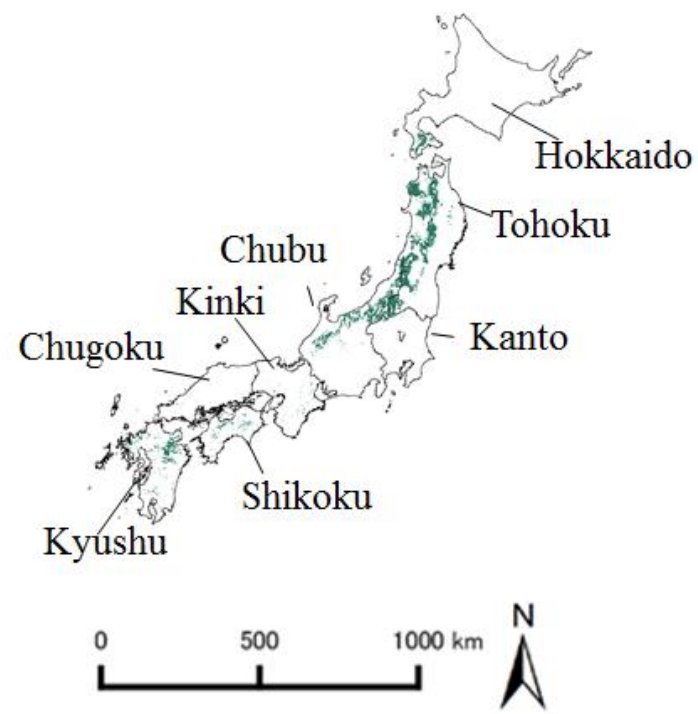

Figure 2. Spatial distribution of beech-dominated deciduous forests derived from the present vegetation map.

\subsection{Data for present climate conditions}

Average annual mesh data for current climate relied on national land numeric information provided by the Ministry of
Land, Infrastructure, Transport and Tourism (MLIT). This numeric information was in the form of mesh data of average annual figures collected by the Meteorological Agency for the period 1981 to 2010 . The data was organized in third mesh for temperature, rainfall and other climatic variables on a month by month basis. The average annual third mesh units for 4 variables were used in this study. These are: TMC, which is the lowest daytime temperature in the coldest month of the year; WI, which is calculated as from the annual average temperature in months with temperatures exceeding $5{ }^{\circ} \mathrm{C}$, excluding temperatures of $-5{ }^{\circ} \mathrm{C}$ and below; PRW, which is the average rainfall between December and March; and PRS, which is the average rainfall between May and September. Figure 3 shows the result of these climate variables displayed in mesh units.

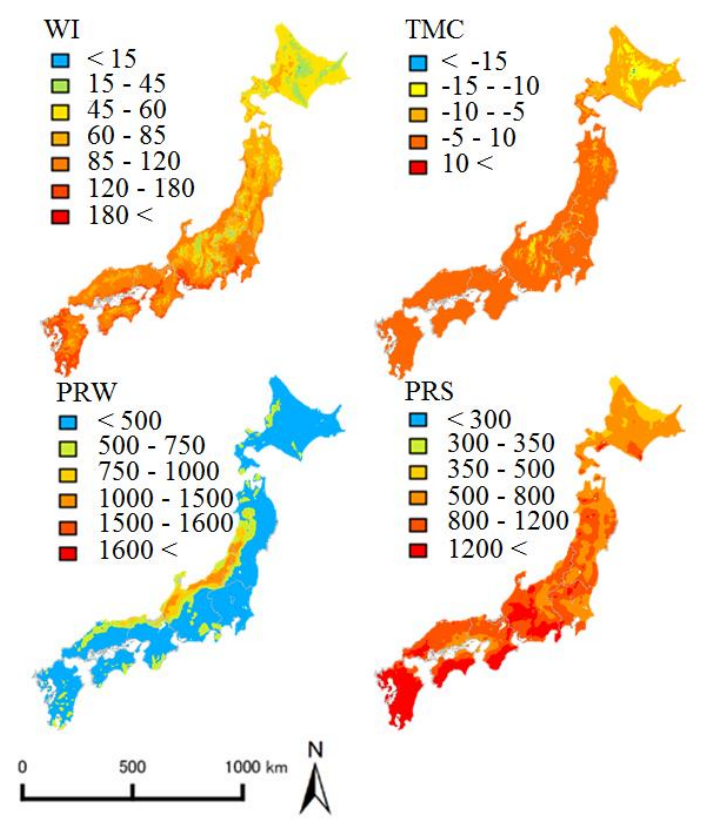

Figure 3. Distribution of present climatic variables.

\subsection{Data and methods for mapping future climatic variables}

The Climate Change Information Database, provided by the Disaster Prevention Research Institute at Kyoto University (Michihiro et al., 2012), was used to set parameters for future climate. This database features three greenhouse gas scenarios (high-emissions, medium-emissions, low-emissions) applied to 29 climate models. The predictions are generated for three time periods; current (1980-1999), near-future (2046-2065) and future (2080-2099). The climatic variables, such as temperature and precipitation, are presented as $80 \mathrm{~km}$ x $80 \mathrm{~km}$ first mesh data.

This study adopted climate change predictions in the upper and lower limit forecasts. The lower limit was based on the CSIROMk3.0 model low-emissions scenario (temperature increased by about $1.8{ }^{\circ} \mathrm{C}$ after 100 years); and the upper limit on the MIROC3.2 model high-emissions scenario (temperature increased by about $4.2^{\circ} \mathrm{C}$ after 100 years). A climate change modification method (Figure 4), modified after Michihiro et al. (2012), was employed to convert the forecasted climate data from first mesh to third mesh for comparison with the current climate datasets. 


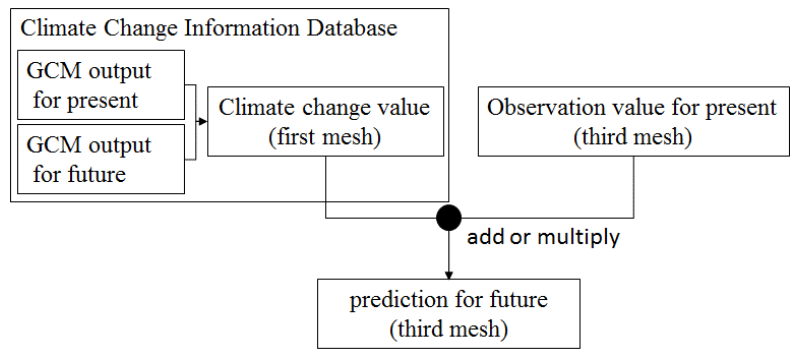

Figure 4. The climate change modification method based on observation value (Modified after Michihiro et al., 2012)

\subsection{Data for geophysical variables}

$250 \mathrm{~m} \times 250 \mathrm{~m}$ fifth mesh data for elevation and slope were obtained from National Land Numerical Information produced by the MLIT. Other variables were obtained from the 1:200,000 scale Fundamental Land Conservation Survey. The fifth mesh data was converted to third mesh for standardization with the other datasets.

\subsection{Development of prediction model for distribution of beech-dominated deciduous forests}

This study's model were constructed to relate the current distribution of beech-dominated deciduous forests with the climatic and geophysical variables. this model were based on random forest (Breiman, 2001), and were used to extract the climatic and geophysical conditions suitable for growth of the beech forests. The ecologically important variables can be objectively identified by determining the statistical importance level of each independent variable (Cutler et al., 2007). Random forests can calculate the importance of each explanatory variable using the two methods of Mean Decrease Accuracy (MDA) and Mean Decrease Gini (MDG), (Calle \& Urrea, 2011; Nicodemus, 2011). In this study, the MDG method was employed. This method measures the decrease in MDG index at each branch in the decision tree for each variable. The variables that produce the greatest decrease in the index are considered to be the most important from a statistical perspective.

\section{RESULTS AND DISCUSSION}

3.1 Future distribution of climatic variables and importance of variables in determining forest distribution

The future distributions of the four climatic variables are shown for the low-emissions and high-emissions scenarios respectively in Figure 5 and Figure 6; and the importance of each explanatory variable in this model is shown in Figure 7.

Winter precipitation (PRW) is the strongest variable, followed by warmth index (WI), topography (TOPO), summer precipitation (PRS) and mean minimum daily temperature of the coldest month (TMC). From this study's model it becomes clear that climatic factors, rather than geophysical, are of greatest importance in determining which areas are suitable for beech forest growth. Snow accumulation in winter appears to be especially vital.

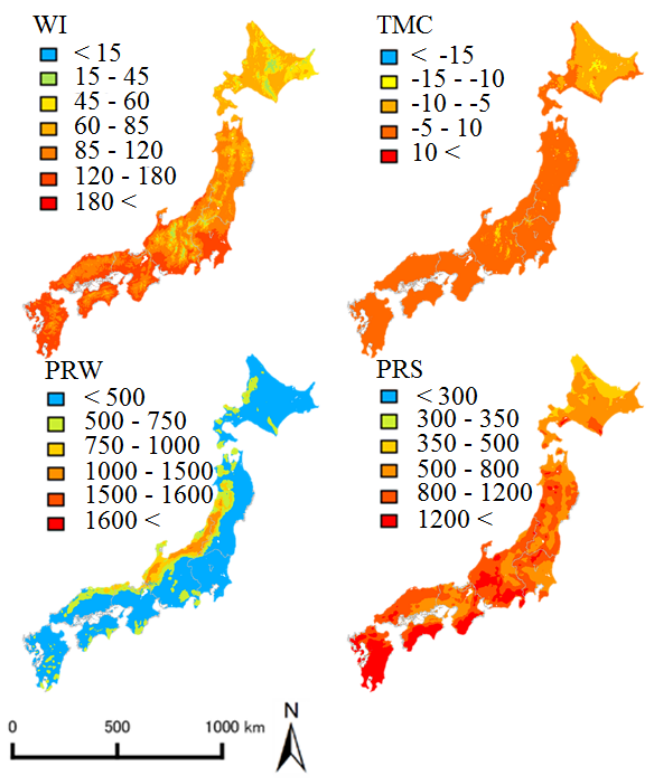

Figure 5. Distribution of future climatic variables for lowemissions scenario.

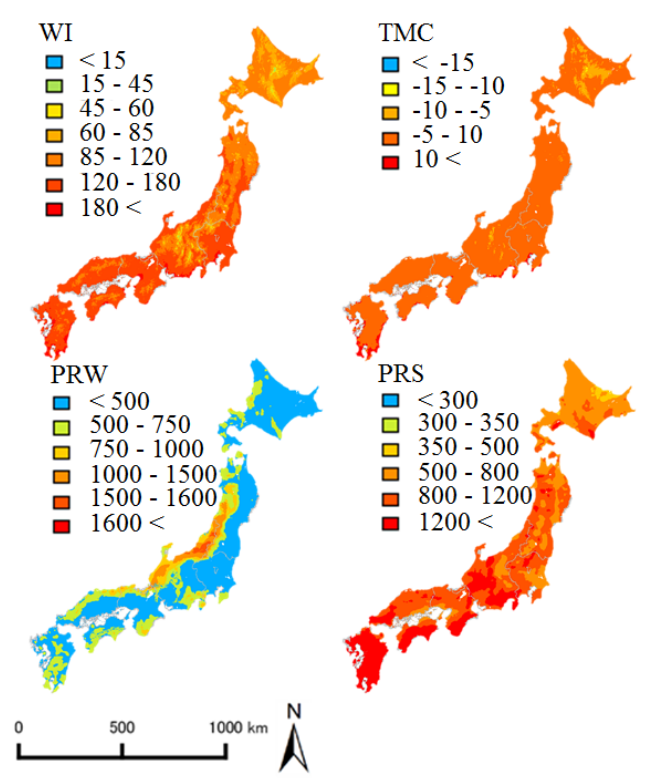

Figure 6. Distribution of future climatic variables for highemissions scenario. 


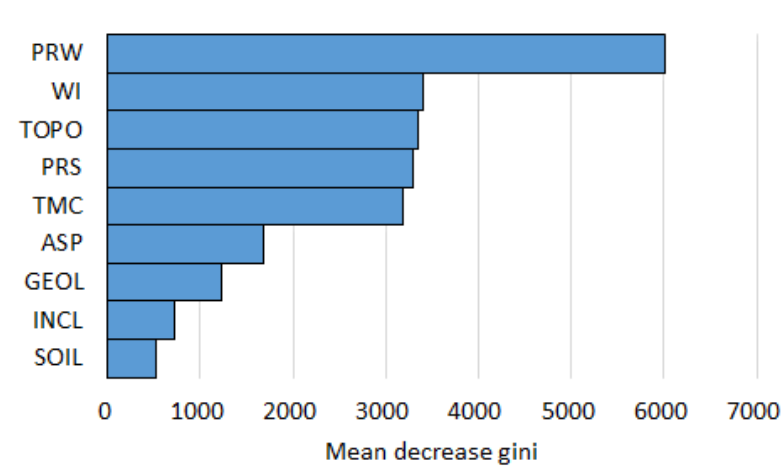

Figure 7. The importance of independent variables as determined by MDG.

\subsection{Distribution of suitable mesh for growth of beech- dominated forests}

The predicted future distributions of beech suitable mesh for current, low-emissions future scenario and high-emissions future scenario are shown respectively in Figures 8a, 8b and 8c.

The same results are compiled by region in Figure 9 . These results confirm a decrease in beech forest area for both future scenarios in all areas of Japan except for the northernmost island of Hokkaido. In both scenarios the beech forests have all but disappeared from the western half of the country (Kinki, Chugoku, Shikoku and Kyushu). A substantial loss of forest can also be seen in the central (Chubu) and north-eastern (Tohoku) parts of the main island, which contain the highest number of current beech forest meshes. The degree of loss is especially staggering for the high-emissions scenario. Hokkaido shows a small increase for both climate change scenarios.
(a)Present
(b)Low-emission
(c)High-emission

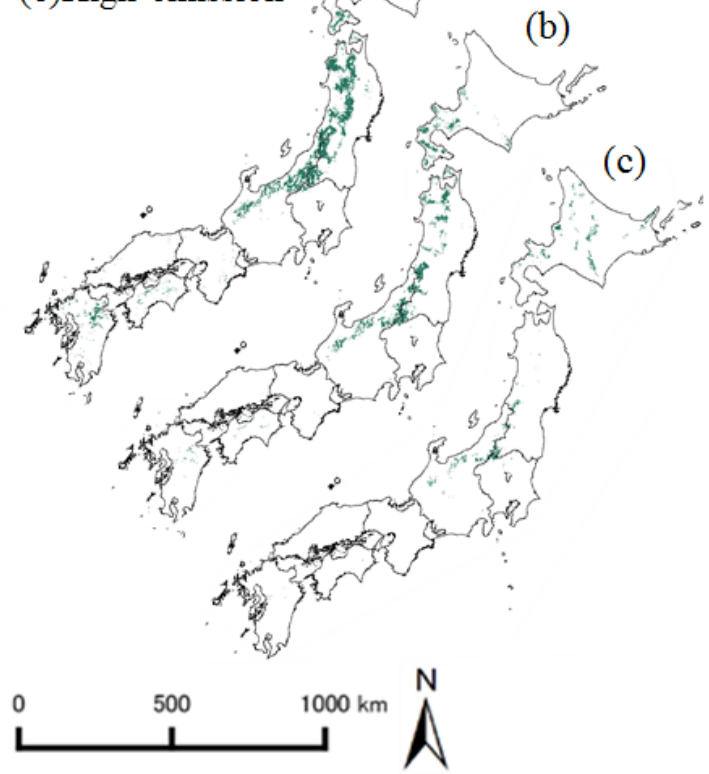

Figure 8. Distribution of growth suitable mesh for beechdominated deciduous forests under present and future climatic conditions.

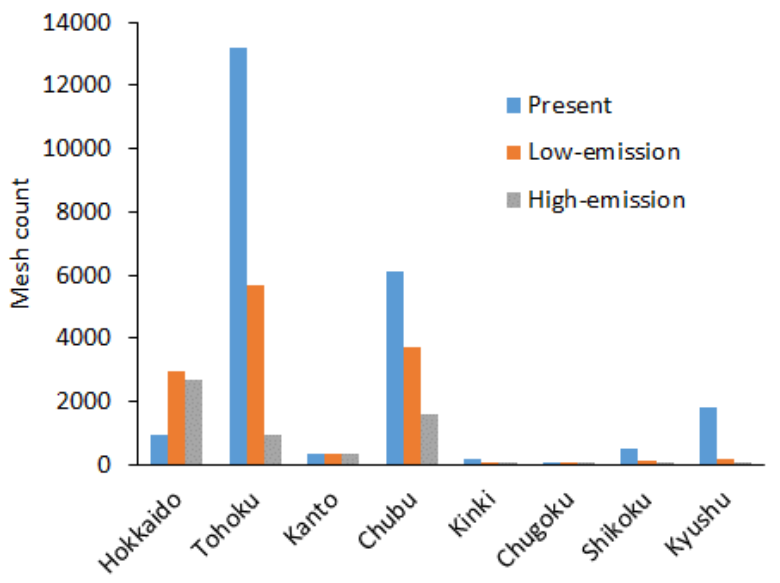

Figure 9. Predicted mesh counts suitable for growth of beechdominated forests mesh for present and two future climate change scenarios.

\section{CONCLUSIONS}

This research attempts to quantify the impact that future climate change will have on a particular ecosystem. Using a random forest, the most important factors in beech forest distribution were determined to be climatic, especially winter precipitation. The results predict that substantial loss of beech forest will occur with even a low emissions scenario, especially in the central and north-eastern parts of Honshu Island, which currently contain the largest expanses of these forests. Some issues remain in the southwestern region, but the results clearly show that remote sensing classification of MODIS data can be an effective tool for predicting and monitoring changes to ecosystems due to global warming.

\section{ACKNOWLEDGEMENTS}

The authors wish to thank Kevin Short for editorial assistance. This research was supported by the Environment Research and Technology Development Fund (1-1405) of the Ministry of Environment, Japan.

\section{REFERENCES}

Breiman, L. 2001. Random forests. Machine learning, pp. 5-32.

Calle, M. L. and Urrea, V. 2011. Letter to the editor: Stability of Random Forest importance measures. Briefings in Bioinformatics, 12(1), pp. 86-89.

Cutler, D. R., Edwards, T. C., Beard, K. H., Cutler, A., Hess, K. T., Gibson, J. and Lawler, J. J. 2007. Random Forests for Classification in Ecology. Ecology, 88(11), pp. 2783-2792.

Harada, I., Hara, K., Park, J., Asanuma, I., Tomita, M., Hasegawa, D., Short, K. and Fujihara, M. 2015. Monitoring of rapid land cover changes in eastern Japan using Terra/MODIS data. ISPRS - International Archives of the Photogrammetry, Remote Sensing and Spatial Information Sciences, XL-7/W3(May), pp. 403-408.

Hioki, Y. 2007. Issues of nation -wide actual vegetation maps from the aspect for application. Landscape ecology and management, 11(2), pp. 107-112.

IPCC 2007. Climate Change 2007 : Summary for Policymakers. IPCC Fourth Assessment Report (Vol. 335). 
Matsui, T., Tanaka, N., Yagihashi, T., Kominami, Y., Tsuyama, I. and Takahashi, K. 2009. Prediction and impact assessment of the changes in suitable habitats for beech (Fagus crenata) forests under climate change scenarios. Global Environmental Research, 14(2), pp. 165-174.

Matsui, T., Yagihashi, T., Nakaya, T., Taoda, H., Yoshinaga, S., Daimaru, H. and Tanaka, N. 2004. Probability distributions, vulnerability and sensitivity in Fagus crenata forests following predicted climate changes in Japan. Journal of Vegetation Science, 15(5), pp. 605-614.

Michihiro, Y., Sato, Y. and Suzuki, Y. 2012. Development and application of GCM database for hydrologic analysis at basin scale. Journal of Japan Society of Civil Engineers, Ser. B1 (Hydraulic Engineering), 68(3), pp. 125-135.

Nicodemus, K. K. 2011. Letter to the editor: on the stability and ranking of predictors from random forest variable importance measures. Briefings in bioinformatics, 12(4), pp. 369-73.

Yamagishi, H. and Kimura, G. 1981. Outcrops of active faults along the Kuromatsunai Lowland, Hokkaido. Earth Science, 35(2), pp. 94-97. 